\title{
Fundamentals of Implementation Science: an intensive course on an emerging field of research
}

\author{
Fundamentos da Ciência da Implementação: um curso intensivo sobre um emergente campo de \\ pesquisa \\ Fundamentos de la Ciencia de la Implementación: un curso intensivo sobre un emergente campo de \\ investigación
}

Karen Gisela Moraes Zepeda ${ }^{1}$ (1) Marcelle Miranda da Silva ${ }^{1}$ (i) Ítalo Rodolfo Silva² (iD Cristina Redko ${ }^{3}$ Sarah Gimbel ${ }^{4}$

1. Universidade Federal do Rio de Janeiro. Rio de Janeiro, RJ, Brasil.

2. Universidade Federal do Rio de Janeiro. Macaé, RJ, Brasil.

3. University of Washington.

Seattle, WA, United States.

4. Wright State University.

Dayton, $\mathrm{OH}$, United States.
Corresponding author:

Marcelle Miranda da Silva.

E-mail: marcellemsufrj@gmail.com

Submitted on 10/20/2017.

Accepted on 02/08/2018.

DOI: 10.1590/2177-9465-EAN-2017-0323

\begin{abstract}
Objective: Report the participation in the Intensive Course on Fundamentals of Implementation Science (IS) in Global Health and present the theoretical scope of IS methods and the potential applicability perspectives for improving global health. Method: Experience report on participation in the course, promoted by the University of Washington, USA, September, 2017. Results: The course introduced IS methodologies and selected case studies, focusing on opportunities and challenges in applying IS in practice. Conclusion: The IS offers tools for the selection of published scientific material and its use through plans, programs, intervention projects, models and protocols that assume diminishing inconsistencies and leverage results on a large scale in health science. Implications for practice: Multidisciplinary teams can benefit from IS training to address in a related way the gaps consistent with progress in the health sciences.
\end{abstract}

Keywords: Global Health; Nursing; Diffusion of Innovation; Health Systems; Translational Medical Research.

\section{Resumo}

Objetivos: Relatar a participação no Curso Intensivo sobre Fundamentos da Ciência da Implementação (Cl) em Saúde Global e apresentar o escopo teórico dos métodos da $\mathrm{Cl}$ e as potenciais perspectivas de aplicabilidade para melhoria da saúde global. Método: Relato de experiência sobre a participação no curso, promovido pela University of Washington, EUA, setembro de 2017. Resultados: $\mathrm{O}$ curso apresentou metodologias da $\mathrm{Cl}$ e estudos de caso selecionados, focalizando oportunidades e desafios na aplicação da $\mathrm{Cl}$ na prática. Conclusão: $\mathrm{A} C \mathrm{Cl}$ oferece ferramentas para seleção de material cientifico publicado e sua utilização por meio de planos, programas, projetos de intervenção, modelos e protocolos que assumam diminuir incongruências e alavancar resultados em larga escala na ciência da saúde. Implicações para a prática: Equipes multidisciplinares podem se beneficiar do treinamento em $\mathrm{Cl}$, para contemplar de forma conexa as lacunas condizentes com o progresso nas ciências da saúde.

Palavras-chave: Saúde Global; Enfermagem; Difusão de Inovações; Sistemas de Saúde; Pesquisa Médica Translacional.

\section{Resumen}

Objetivos: Relatar la participación en el Curso Intensivo sobre Fundamentos de la Ciencia de la Implementación (Cl) en Salud Global y presentar la programación teórica de los métodos $\mathrm{Cl}$ y potenciales perspectivas de aplicabilidad para la mejoría de la salud global. Método: Relato de experiencia sobre el curso, propuesto por la University of Washington, EE.UU., 2017. Resultados: El curso presentó metodologías de la $\mathrm{Cl}$ y estudios de caso, enfocando oportunidades y desafíos en su aplicación en la práctica. Conclusión: La Cl ofrece herramientas para la selección de material científico y su utilización a través de planes, proyectos de intervención y protocolos, que asumen disminuir incongruencias y aprovechar resultados en la ciencia de la salud. Implicaciones para la práctica: Equipos multidisciplinarios pueden beneficiarse del entrenamiento en $\mathrm{Cl}$ para contemplar de forma conexa las lagunas que concuerdan con el progreso en las ciencias de la salud.

Palabras clave: Salud Global; Enfermería; Difusión de Innovaciones; Sistemas de Salud; Investigación en Medicina Traslacional. 


\section{INTRODUCTION}

Science arises as a necessity for the understanding and intervention of humanity in the face of the elements that constitute existence. It configures as a dynamic system while it goes through and progresses in parallel to social challenges. In this sense, contemplating this understanding means meeting science with conscience, that is, to seek the necessary connections between scientific knowledge and the social demands that call for sustained solutions in the scientific field, which remains under construction. , $^{1,2}$

As globalization, that was widely diffused in the twentieth century and boosted at the beginning of the $21^{\text {st }}$ century, important advances in the economic, social, cultural, technicalscientific and biotechnological fields were achieved. However, the progress of science does not seem to have matched the demands of health across the globe.

The 1990 report prepared by the Commission on Health Research for Development of the World Health Organization (WHO) on prevalent diseases, its causes and consequences, impacted showing that "less than $10 \%$ of global spending on research were targeted for diseases responsible for more than $90 \%$ of the global burden of health problems". 3:37

These diseases prevail in low-income countries, which are neglected even by the pharmaceutical industry. The global trend in health emphasizes the need to recognize and assess health challenges, since the issue of diseases and their consequences are research priorities, and their importance has increased fivefold since the publication of the aforementioned report. ${ }^{3}$

Global health portrays "health issues that transcend national boundaries and require interventions in global flows that determine people's health, while requiring new forms of governance at the national and international levels". 4:268 Thus, faced with the constant changes in health and disease patterns of contemporary times, it becomes fundamental that the debate about the demands of care and the determinants and conditioning of health be socialized, in consonance with the plural local reality lived by the social actors involved, including stakeholders like the population, working professionals, and public health policymakers.

In view of the complexity involved in health demands, across the globe, respecting their contextual specificities, it is necessary to consider the importance of new strategies that promote mechanisms of intervention based on relevant knowledge. It is evident from this reality the importance of thinking about the connections between the challenges of global health and the strategies that articulate science and objective reality.

In this sense, an emerging field of study, Implementation Science (IS), works systematically with the problems of research, testing of interventions and evaluation of the real impact of programs to contribute to the practice in global health. The IS includes a study of methods that are focused on the search for central elements of interventions based on scientific evidence that can impact health systems. In addition, it focuses on the "front" actors, directly involved in the research field, since their developments depend on the sustainability of health interventions in challenging environments. ${ }^{5}$

As is common in areas emerging in science, IS is a broad field of research, terminology and definition that can be explained from a variety of perspectives and is recognized under various names, namely "dissemination research", "implementation research" , "search for results", "health systems research", "operational research", "quality improvement research", "translational research", among others.

The leading international journal, "Implementation Science," in 2006, defined it as the "scientific study of methods to promote the systematic capture of research findings and other evidence-based practices (EBP) in routine practice, to quality and effectiveness of health services" .6:1

In addition, IS intends to understand the behavior of health professionals and others involved as key elements in the adoption of evidence-based interventions, and address rigorous scientific findings to places that have limited health resources to save more lives. ${ }^{7}$ It seeks, so to speak, to translate research into practice, essentially responding to the following questions: what are the key components of the intervention to work? How do we ensure the best application of the intervention for all?

The political component of health systems research directs attention to the instruments used for decision-making on projects, but also to the influencing forces of decisions: social actors, power and politics, institutions, interests and ideas. ${ }^{8}$ Therefore, the interaction of these elements, as well as the quality of these interactions, allows us to consider whether it is a complex phenomenon, that is, a phenomenon constituted and fed by the diverse interaction. ${ }^{1}$ Likewise, strategies to deal with this reality also need to be complex.

The last decades have witnessed notable theoreticalpractical changes applied to global health in the scientific field. However, the translation of the findings into practice has been time consuming and uneven. As a result, innumerable discoveries, possibly applicable to health, are not, causing gaps between what one has as knowledge about the resolution of health problems and the application of the necessary tools to its accomplishment.

With the help of IS, it is intended to apply systematic research, measure and evaluate results obtained from rigorous scientific analyzes, in order to identify the challenges in the effective replication and large-scale adaptation of evidencebased interventions at the various sites globally.

Extracting the results from research carried out and incorporating them into the practical field is an exercise that has been improved in recent years. However, the health field still lacks an information infrastructure that provides the connection between those who produce knowledge and those who need to apply it. ${ }^{9,10}$ 
Thus, the objective of this study was to present the experience of participation in the Intensive Course on Fundamentals of Implementation Science in Global Health, promoted by the University of Washington; and present the discussion about the theoretical scope of the method and perspectives of applicability for improvement of global health indicators.

\section{METHOD}

This is a descriptive, experience-based study of participation in the Intensive Course on Fundamentals of Implementation Science in Global Health, promoted by the University of Washington Department of Global Health, carried out at the Magnuson Health Sciences Building, in the city of Seattle, in the state of Washington, United States of America (USA).

The accomplishment of this activity was part of the work plan of the Doctorate in nursing course of one of the authors, carried out at the Anna Nery Nursing School (EEAN), Federal University of Rio de Janeiro (UFRJ).

The $4^{\text {th }}$ Annual Conference to mark the Fundamentals of Implementation Science in Global Health met 60 participants of broad cultural, professional and institutional diversity, which was double the previous meeting in 2016. Participants included countries such as the USA, Greece, Ukraine, Malawi, Kenya, Nigeria, Uganda, China, India, Peru and Brazil. In the midst of the various protagonists, ministers of health from some African countries attended the course, mostly from the health team, and other participants such as doctors, nurses, pharmacists, biomedical and engineers, enrolled in Stricto Sensu graduate programs from renowned foreign universities, such as Harvard and Johns Hopkins, as either students or researchers and/or professors.

The course, in its first week, covered theoretical concepts in didactic sessions, including interactive lectures on the Implementation Science in Global Health for five days, from August 28 to September 1, 2017, from 08:00 am to 5:00 p.m., totaling 40 hours. It featured concepts and appropriate scientific IS methodologies, with emphasis on management tools, health systems, applied engineering and public policies. To promote group discussions, the main strategy used was the presentation of case studies that represent public health problems of global importance, focusing on ways of thinking about IS in its approach, evaluation, adequacy, use of theoretical-guide models, and implementation of large-scale interventions, focusing on successes or failures in implementation 10 to 20 years after innovation.

The following week, with optional participation, took place from September 5 to 8, 2017. The practical sessions of the course lasted four days, which involved the opportunity to work alongside global health faculty mentors in the development of an implementation research protocol, with the goal of working through the critical elements of specific aims.
The present report addresses the experience in the participation of the first week of the course, contributing to the dissemination of its theoretical scope.

The classes were organized with a timely agenda previously stipulated and accessible through a virtual platform, which allowed online access to the participants on all didactic-theoretical content addressed in the course. The platform was fed by the administrative assistant, with classes taught daily in PDF format, for the simultaneous access of the participants to the classes and other virtual contents of analogous reading, such as scientific articles and case studies. The scope of the course, in its didactic sessions, broadly congregated the meanings and examples of impact research in the field of IS, and the various researchers, professors and other speakers had expertise, greatly enriching the content taught.

On the third day of the course, a technical visit was offered by the University of Washington to a philanthropic institution - the Bill \& Melinda Gates Foundation - that works in several locations around the globe, and contributes to research for improvement in health, accessibility to humanitarian services, health education and financing, and others, populations in need and other initiatives. The University of Washington alone invested about \$ 279 million in 2017 to continue and expand health-care programs around the world over the next 10 years. ${ }^{11}$ This visit culminated in a meeting with the Foundation's program coordinators for a dialogue preceded by discussions among the participants. Chart 1 shows the programming of the first week of the course.

The promotion of cultural exchange through the technical visit was initially offered by directing the participants to a museum of the Gates Foundation, open to the public, where investments and results from research of the Institute are exhibited in an artistic way. Investments are wide ranging from the creation of sustainable alternatives in the elaboration of sanitary devices in cities that lack water, to educational financial actions that allow the teaching of the sustainable use of money to farmers of a community dominated by the male chauvinism culture.

Participants were then referred to the annex building, which concentrates meetings, lectures and other informative activities between investment stakeholders and those responsible for promoting research. The meeting culminated in the presentation of several individuals responsible for ongoing research and a session that allowed for an exchange of questions and answers on new and future investments of the Institute, as well as the students involved and possible partnership interests.

Regarding the ethical aspects of human research, there was no need for an ethical evaluation in the USA, dispensing with the use of the Term of Consent for other course participants and professors, considering any ideas that may have been explored here in the scope of the discussions and socializations in the classroom. However, the PhD research project was approved by the Research Ethics Committee of the EEAN/UFRJ (opinion no. 1,920,588), following the Resolution of the National Health Council no. 466/2012. 
Chart 1. Didactic Coursework of the first week of the Intensive Course in Fundamentals of Implementation Science in Global Health.

\begin{tabular}{|c|c|c|c|c|c|}
\hline Time & $08 / 28 / 2017$ & $08 / 29 / 2017$ & $08 / 30 / 2017$ & $08 / 31 / 2017$ & $09 / 01 / 2017$ \\
\hline 9:00-10:15 & $\begin{array}{l}\text { Welcome and } \\
\text { introductions }\end{array}$ & $\begin{array}{l}\text { Impact Evaluation 2a: } \\
\text { Quasi-experimental } \\
\text { designs in IS (time } \\
\text { series) } \\
\text { Brandon Guthrie }\end{array}$ & $\begin{array}{l}\text { Gates Foundation } \\
\text { Visit } 9 \mathrm{~h}-13 \mathrm{~h}\end{array}$ & $\begin{array}{l}\text { Quality } \\
\text { Improvement as a } \\
\text { Management Tool } \\
\text { Sarah Gimbel }\end{array}$ & $\begin{array}{l}\text { Organizational } \\
\text { Assessment and } \\
\text { Readiness } \\
\text { Bryan Weiner }\end{array}$ \\
\hline $10: 15-11: 30$ & $\begin{array}{l}\text { Introduction to IS } \\
\text { Kenny Sherr } \\
\text { Judy Wasserhheit }\end{array}$ & $\begin{array}{l}\text { Impact Evaluation 2b: } \\
\text { Quasi-experimental } \\
\text { designs in IS } \\
\text { (differences, } \\
\text { in-differences, } \\
\text { regression } \\
\text { discontinuity, etc.) } \\
\text { Brad Wagenaar }\end{array}$ & $\begin{array}{l}\text { Transportation } \\
\text { provided by the } \\
\text { Course }\end{array}$ & $\begin{array}{l}\text { Case Study: Topic } \\
\text { TBD } \\
\text { Carey Farquhar } \\
\text { and Sarah } \\
\text { Masyuko }\end{array}$ & $\begin{array}{l}\text { Case Study: } \\
\text { Task-sharing } \\
\text { mental health } \\
\text { interventions in } \\
\text { Kenya } \\
\text { Shannon Dorsey }\end{array}$ \\
\hline 13:00-14:15 & Lunch & Lunch & & Lunch & Lunch \\
\hline $14: 15-15: 30$ & $\begin{array}{l}\text { Surveillance to } \\
\text { measure impact and } \\
\text { inform strategies } \\
\text { Charbel el Bcheraoui }\end{array}$ & $\begin{array}{l}\text { Impact Evaluation 3: } \\
\text { Experimental designs } \\
\text { in IS (Cluster RCT, } \\
\text { Stepped Wedge) } \\
\text { Jim Hughes }\end{array}$ & $\begin{array}{l}\text { Economic } \\
\text { Analysis and Cost } \\
\text { Effectiveness } \\
\text { Analysis } \\
\text { Ruannne Barnabas }\end{array}$ & $\begin{array}{l}\text { Dissemination } \\
\text { Research }\end{array}$ & $\begin{array}{l}\text { Article Discussion: } \\
\text { Application of } \\
\text { IS Theory and } \\
\text { Frameworks }\end{array}$ \\
\hline
\end{tabular}

\section{RESULTS AND DISCUSSION}

In general, it takes about 17 years to translate $14 \%$ of the original research into a benefit for the care provided to health users. ${ }^{10}$

A meta-analysis performed in the Medical Literature Analysis and Retrieval System Online (MEDLINE) database, between 1966 and 1992, pointed out that 13 years were necessary to recommend, for example, the use of thrombolytic drugs in the treatment of acute myocardial infarction after the publication of randomized controlled trials (RCTs) indicative of therapeutic efficacy. In addition, it took 10 years for the instructional recommendations for treatment of new therapies such as these to come up in didactic medical books. ${ }^{12}$

This shows that there is a delay between learning, the implementation of effective solutions and the translation of these to local needs of specific populations, that is, investments in research do not reflect, as they should, the societal benefits. Thus, disease deaths that respond to effective low-cost prevention and/ or treatment strategies, such as maternal death from malaria, in-hospital mortality from Human Immunodeficiency Virus (HIV), or any other preventable diseases, are a warning in the field of public health nowadays, since they point to global deficits. 
The reason behind this seems to be the "abyss" that separates the exchange of knowledge between research, public policy and what is done in practice, what WHO refers to as the "know-do gap" (the gap between knowledge and practice). ${ }^{13}$ Moreover, the production and consumption of intellectual capital manifests through research that often makes possible new findings in search of effective and efficient health care. ${ }^{6}$ Faced with a constantly changing world, public health policymakers often address clinical guidelines and best practices in health from adjoining sites with the aim of impacting their own local health policies without, at least, resort to systematic studies that demonstrate that health outcomes vary across settings and contexts, globally. ${ }^{7}$

Based on this reality, an example cited during the course endorses that despite increasing investments in global health and the availability of effective low-cost interventions to prevent mother-to-child HIV transmission (pMTCT) in low and middleincome countries with high HIV rates, the translation of scientific advances into the effective distribution of strategies has been slow, uneven and incomplete. ${ }^{14}$

As a result, pediatric HIV infection remains largely uncontrolled. A five-step, facility-level systems analysis and improvement intervention (SAIA) was designed to maximize effectiveness of pMTCT service provision by improving understanding of inefficiencies (step one: cascade analysis), guiding identification and prioritization of low-cost workflow modifications (step two: value stream mapping), and iteratively testing and redesigning these modifications (steps three through five). ${ }^{14}$

The SAIA intervention is a pragmatic trial that has the potential benefit of improving maternal and infant outcomes by reducing drop-offs along the PMTCT cascade, designed to provide simple tools to guide the decision-making for PMTCT program staff at the facility level, and to identify low cost, contextually appropriate pMTCT improvement strategies.

Therefore, it is necessary to understand how research results and other evidence inform and guide the practice. ${ }^{15}$

There are four principles for achieving EBP, namely: "clinical decision making that considers the best evidence available, the context in which care is provided, client preference, and the judgment of the health professional". ${ }^{16: 85}$ This denotes the unique character of the research that IS proposes to carry out, taking into account the specificities of the intervention implemented in the light of the best available scientific evidence.

A number of health, engineering, and business researchers are showing interest in using tools, such as scientific models of systematic methods, that allow for the dissemination of EBPs and thus dimension on a large-scale findings rigorously evaluated that meet the needs of disparate populations. ${ }^{7}$ Research evaluation, however, needs to be conducted under "real world" conditions in order to meet the health challenges of the $21^{\text {st }}$ century, which requires concise methodological development. ${ }^{17}$
The IS aims to improve the quality of health at the various levels in which it is practiced, which often causes confusion with Quality Improvement (QI), since the pretension is the same, but the QI deals with specific problems underlying several levels of health care service to design and conduct research that can improve the target problem. IS, on the other hand, is based on evidence-based research that is rarely used to identify and achieve quality gaps in the various scenarios of health promotion and assistance. ${ }^{18}$

The dissemination of EBPs can occur using models, but rather a theory should form the basis of the phenomenon studied in order to explain it. The theory is evidenced "in the form of a theoretical framework of how the system of interest functions at the level of interest"; $17: 7$ in addition, the theory offers a "common language to explore and identify influences in practice, enhancing the transparency of the description and development of the intervention". 17:127

Although theory and model are often presented as synonyms in the literature, they have different concepts, but both increase the effectiveness of interventions by helping to focus them on the essential behavioral change processes that can be quite complex. Theories "are abstract, widely applicable," and serve to systematically understand events or behaviors by providing "interrelated concepts, definitions, and propositions that explain or predict events by correlating variables," while models "are strategic, for planning actions that provide a systematic way to develop, conduct and evaluate interventions". 19:2

The use of theoretical models that guide implementation may be able to promote more sustainable transitions, that is, to allow changes in practice to prevail over a longer period; however, the challenge lies in the still arduous task of translating different theories of implementation and models for actions themselves. ${ }^{20}$ There is a range of different types of knowledge, theoretical perspectives and models used in IS that were presented during the course, namely: Theoretical Domains Framework, The Consolidated Framework for Implementation Research (CFIR), The RE-AIM model, among others, which serve to address questions related to this translation of research in practice and to measure results and consequent impacts that guide the evaluation of alternative programs in health. ${ }^{17}$

During the course, the didactic sessions addressed examples of previous and ongoing research, as well as desired, effective or inert results, and theoretical and practical gaps using IS. Research designs to measure large-scale health impacts of what were once considered the "gold standard" of contemporary medicine nowadays do not attempt to increase the internal validity of new research designs, thanks to the increasing use of randomized controlled trials (RCTs). This movement has fostered the search for quality standards in clinical research, which itself has generated the Evidence-Based Medicine Movement and Cochrane Collaboration partnership, resulting in important advances in the availability and quality of the scientific evidence obtained. ${ }^{21}$ 
The research methods often used in IS to influence practices in the real world and to test complex interventions include the use of conceptual models and the use of the mixed methods approach in research in order to capture the complexity and heterogeneity of the mechanisms, processes and results of major changes in systems. Complex interventions encompass the measurement of relationships that have variable interactions, over which, for example, there is uncertainty and unpredictability in the face of social behavior. The exercise of disseminating changes that do not fit directly into a given culture also signals a complex intervention. ${ }^{17}$

The DeWorm3 Hybrid Trial, presented during the course, exemplifies an ongoing hybrid study that, given the global epidemiological profile of the estimated 1.5 billion people infected with soil-transmitted helminths (STH), whose persistent infections can lead to malnutrition and anemia, resulting in the physical and cognitive delay of children and reduced productivity and income generation in adults, seeks to develop a viable and effective approach that uses a plan to interrupt the transmission of STH on a large scale. Such a plan will be an IS strategy in countries such as Malawi, India, Benin, Kenya, and others, based on studies demonstrating strategies different from current WHO guidelines, which recommends treating school children annually in places where STH prevalence falls by $20 \%$ and $50 \%$, and biannually where it exceeds $50 \% .{ }^{22}$

To achieve the global goal of eliminating STH morbidity in children by 2020 , WHO advocates regular treatment of at least $75 \%$ of children in endemic areas (an estimated 873 million). However, in the scientific literature, the debate about the best strategy for managing STH infections replaces the current morbidity control with interruption of transmission, since it is estimated that the reduction of morbidity and the goal of stopping transmission would be more likely and faster if the coverage was expanded to aggregate adult treatment. Concomitant emphasis on education, sustainability of health hygiene programs, and the need to broaden the scope of research to investigate cost-effective and feasible options for alternative treatments for the interruption of transmission are also encouraged. ${ }^{23}$

The evaluation of complex interventions must go through evaluation processes in order to explain discrepancies between expected and observed results. Complex interventions and large-scale transformations are often used to act at collective levels, such as communities using public health programs or even groups of health professionals. However, at times when various health promotion interventions are tested in the same community, or a single practitioner promotes various types of patient care, for example, there is "contamination" of the sample, leading to bias. To address such problems, methods such as cluster randomized controlled trials (cRCT) and stepped-wedge trials, have grown popularly. ${ }^{17}$
Although RCTs are the gold standard for pharmaceutical testing for efficacy and safety, the provision of health services is less likely to be subject to scientific analysis. ${ }^{7}$ Indeed, RCTs are underpinned by Karl Popper's post-positivist scientificrealist philosophy as science and technology began to exert an increasingly strong dominion over the production of knowledge. Realism "is the belief that there is an external reality that exists independently of human perception", ${ }^{24: 1}$ since those who produce science intend to describe and explain reality. The statement consistent with this philosophical tradition, that "truth" is only apparent if it is empirically tested in the real world, supports the operability of RCTs. However, they are not able to take into account human reasoning, or to assess how or why an intervention achieves results. ${ }^{17,24}$

Thus, mixed methods gain space, and it is substantial that intervention and evaluation drawings aim to represent the context, process, practice, and outcomes of the changes required, implemented, tested, and evaluated in health systems, in looking for ways in which quantitative and qualitative methods allow the understanding of the phenomenon studied. ${ }^{17}$

In IS, research designs using mixed methods have been used to develop a scientific basis for better understanding and overcoming barriers in the implementation of EBPs. Mixed methods allow an approach that combines the quantitative and qualitative use of information to provide a better understanding of the research, including focus on data collection, analysis and use. ${ }^{25}$ The outcomes of the use of more than one research method in IS aim to contribute to the effectiveness, acceptability, feasibility and adequacy of the implementation strategies from the perspective of the actors involved, who have different experiences, in order to adapt the best practices in a sustainable way. ${ }^{26}$

\section{CONCLUSION}

The course has fulfilled the objectives outlined in an enthusiastic and effective manner, offering a wide range of information on IS, its intentions, achievements, challenges, repercussions and developments in the context of global health. The health challenges of the $21^{\text {st }}$ century affect everyone globally, but with consequences and repercussions that are not captured in all the areas in which they propagate, so that interpreting health responses, singular in their individuality, but plural among the various contexts in which they happen, is the subject of IS research, inherent in the evolution of improvements in the health of all.

The course emphasized current and future challenges in the way biomedical research propagates, which has a broad-spectrum theoretical-didactic framework of potential dispersion, but which, even in the face of all scientific 
achievements, cannot be developed for the next millennium if the pertinent dissemination of its findings for practice remains at the level of the last century. Furthermore, the wide range of information that remains static in virtual databases does not ensure successful implementations by themselves. Their compilation and consequent use, testing, comparison and evaluation in researches globally is necessary, in order to reduce the "know-do gap" observed between the literature and the real world.

In order to advance global health research, this experience report found the possibility of obtaining knowledge beyond the national level, which endorses IS's current recommendations to disseminate information on a large scale in an inclusive way, in a world that is progressively transmuted into new daily challenges in different social realities, service organizations and public health policies. It is up to advocacy for new partnerships and sustainable engagements addressed to pressing research problems to contemplate them in an effective, resilient and resolute manner.

\section{REFERENCES}

1. Morin E. Ciência com consciência. $13^{\mathrm{a}}$ ed. Rio de Janeiro (RJ): Bertrand; 2010.

2. Demo P. Aprender como autor. São Paulo (SP): Atlas; 2015

3. Organização Mundial da Saúde (OMS). Relatório mundial da saúde 2013. Pesquisa para a cobertura universal de saúde [Internet] 2014 [cited 2017 Sep 15]. Available from: http://apps.who.int/iris/ bitstream/10665/85761/26/9789248564598_por.pdf?ua=1

4. Preto VA, Batista JMFB, Ventura CAA, Mendes IAC. Refletindo sobre as contribuições da enfermagem para a saúde global. Rev Gaúcha Enferm [Internet]. 2015; [cited 2018 Apr 25]; 36(n.esp):26770. Available from: http://www.scielo.br/scielo.php?pid=S198314472015000500267\&script=sci_abstract

5. Bloomrosen M, Detmer DE. Informatics, evidence-based care, and research; implications for national policy: a report of an American Medical Informatics Association health policy conference. J Am Med Inform Assoc [Internet]. 2010 Mar/Apr; [cited 2018 Apr 25]; 17(2):115 23. Available from: https://www.ncbi.nlm.nih.gov/pmc/articles/ PMC3000781/

6. Eccles MP, Mittman BS. Welcome to Implementation Science. Implement Sci [Internet]. 2006; [cited 2017 Sep 30]; 1(1):1-3. Available from: https:// implementationscience.biomedcentral.com/track/pdf/10.1186/17485908-1-1?site=implementationscience.biomedcentral.com

7. Madon T, Hofman KJ, Kupfer L, Glass RI. Public health. Implementation science. Science [Internet]. 2007 Dec; [cited 2018 Apr 25]; 318(5857):1728-9. Available from: https://www.ncbi.nlm.nih.gov/ pubmed/18079386

8. Ghaffar A, Gilson L, Tomson G, Viergeverd R, Røttingene JA. Where is the policy in health policy and systems research agenda? Bull World Health Organ [Internet]. 2016 Apr; [cited 2018 Apr 25]; 94(4):306-8. Available from: https://www.ncbi.nlm.nih.gov/pubmed/27034524

9. Weed LL. New connections between medical knowledge and patient care. BMJ [Internet]. 1997 Jul; [cited 2018 Apr 25]; 315(7102):231-5 Available from: https://www.ncbi.nlm.nih.gov/pubmed/?term=9-\%09We ed+LL.+New+connections+between+medical+knowledge+and+patien $\mathrm{t}+$ care
10. Balas EA, Boren SA. Managing Clinical Knowledge for Health Care Improvement. Yearb Med Inform [Internet]. 2000; [cited 2018 Apr 25]; (1):65-70. Available from: https://www.ncbi.nlm.nih.gov/ pubmed/27699347

11. The Seattle Times. Historic gift: Gates Foundation gives $\$ 279$ million to University of Washington [Internet]; [cited 2017 Sep 20]. Available from: https://www.seattletimes.com/seattle-news/science/historic-gift-gatesfoundation-gives-279-million-to-university-of-washington/

12. Antman EM, Lau J, Kupelnick B, Mosteller F, Chalmers TC. A comparison of results of meta-analyses of randomized control trials and recommendations of clinical experts. Treatments for myocardial infarction. JAMA [Internet]. 1992 Jul; [cited 2018 Apr 25]; 268(2):240-8. Available from: https://www.ncbi.nlm.nih.gov/pubmed/?term=A+comparison+of+re sults+of+meta-analyses+of+randomized+control+trials+and+recommen dations+of+clinical+experts $\% 3 A+$ treatments+for+myocardial+infarction

13. van den Driessen Mareeuw F, Vaandrager L, Klerkx L, Naaldenberg $\mathrm{J}$, Koelen M. Beyond bridging the know-do gap: a qualitative study of systemic interaction to foster knowledge exchange in the public health sector in The Netherlands. BMC Public Health [Internet]. 2015 Sep; [cited 2018 Apr 25]; 15:922. Available from: https://www.ncbi.nlm.nih.gov/pub $\mathrm{med} /$ ?term=Beyond+bridging+the+know-do+gap $\% 3 \mathrm{~A}+\mathrm{a}+$ qualitative+s tudy+of+systemic+interaction+to+foster+knowledge+exchange+in+th e+public+health+sector+in+The+Netherlands

14. Sherr K, Gimbel S, Rustagi A, Nduati R, Cuembelo F, Farquhar C, et al Systems analysis and improvement to optimize pMTCT (SAIA): a cluster randomized trial. Implement Sci [Internet]. 2014 May; [cited 2018 Apr 25] 9:55. Available from: https://www.ncbi.nlm.nih.gov/pubmed/24885976

15. Fawcett J, Garity J. Evaluating research for evidence-based nursing practice: research and evidenced-based nursing practice. Philadelphia (PA): F.A. Davis Company; 2009.

16. Pearson A, Wiechula R, Court A, Lockwood C. A re-consideration of what constitutes "evidence" in the healthcare professions. Nurs Sci $\mathrm{Q}$ [Internet]. 2007 Jan; [cited 2018 Apr 25]; 20(1)85-8. Available from: https://www.ncbi.nlm.nih.gov/pubmed/?term=A+Re-consideration+of+ what+constitutes+\%E2\%80\%9Cevidence $\%$ E2\%80\%9D+in+the+healt hcare+professions

17. Raine R, Fitzpatrick R, Barratt H, Bevan G, Black N, Boaden R, et al. Challenges, solutions and future directions in the evaluation of service innovations in health care and public health. Health Serv Deliv Res [Internet]. 2016 May; [cited 2018 Apr 25]; 4(16). Available from: https:// www.ncbi.nlm.nih.gov/books/NBK361182/

18. Bauer MS, Damschroder L, Hagedorn H, Smith J, Kilbourne AM. An introduction to implementation science for the non-specialist. BMC Psychol [Internet]. 2015 Sep; [cited 2018 Apr 25]; 3:32. Available from: https://www.ncbi.nlm.nih.gov/pubmed/26376626

19. Tabak RG, Khoong EC, Chambers DA, Brownson RC. Bridging research and practice: models for dissemination and implementation research. Am J Prev Med [Internet]. 2012 Sep; [cited 2018 Apr 25]; 43(3):337-50. Available from:https://www.ncbi.nlm.nih.gov/pubmed/?term=Bridging+Research+a nd+Practice+Models+for+Dissemination+and+Implementation+Research

20. McKillop A, Shaw J, Sheridan N, Gray CS, Carswell P, Wodchis WP et al. Understanding the Attributes of Implementation Frameworks to Guide the Implementation of a Model of Community-based Integrated Health Care for Older Adults with Complex Chronic Conditions: A Metanarrative Review. Int J Integr Care [Internet]. 2017 Jun; [cited 2018 Apr 25]; 17(2):10. Available from: https://www.ncbi.nlm.nih.gov/ pubmed/?term=Understanding+the+Attributes+of+Implementation+F rameworks+to+Guide+the+Implementation+of+a+Model+of+Commu nity-based+Integrated+Health+Care+for+Older+Adults+with+Comple $\mathrm{x}+$ Chronic+Conditions $\% 3 \mathrm{~A}+\mathrm{A}+$ Metanarrative+Review

21. Victora CG, Habicht JP, Bryce J. Evidence-based public health: moving beyond randomized trials. Am J Public Health [Internet]. 2004 Mar; [cited 2018 Apr 25]; 94(3):400-5. Available from: https://www.ncbi.nlm.nih.gov/ pubmed/14998803 
22. Anderson RM, Turner HC, Truscott JE, Hollingsworth TD, Brooker SJ. Should the Goal for the Treatment of Soil Transmitted Helminth (STH) Infections Be Changed from Morbidity Control in Children to Community-Wide Transmission Elimination? PLoS Negl Trop Dis [Internet]. 2015 Aug; [cited 2018 Apr 25]; 9(8):e0003897. Available from: https://www.ncbi.nlm.nih.gov/pubmed/?term=Should+the+Goal +for+the+Treatment+of+Soil+Transmitted+Helminth+(STH)+Infections $+\mathrm{Be}+$ Changed+from+Morbidity+Control+in+Children+to+CommunityWide+Transmission+Elimination\%3F

23. World Health Organization (WHO). Preventive chemotherapy in human helminthiasis: Coordinated use of anthelminthic drugs in control interventions: a manual for health professionals and programme managers. Geneva: World Health Organization; 2006.
24. Porter S, McConnell T, Reid J. The possibility of critical realist randomized controlled trials. Trials [Internet]. 2017 Mar; [cited 2018 Apr 25]; 18(1):133. Available from: https://www.ncbi.nlm.nih.gov/pub $\mathrm{med} /$ ?term=The+possibility+of+critical+realist+randomized+controlle d+trials

25. Palinkas LA, Aarons GA, Horwitz S, Chamberlain P, Hurlburt M, Landsverk J. Mixed method designs in implementation research. Adm Policy Ment Health [Internet]. 2011 Jan; [cited 2018 Apr 25]; 38(1):4453. Available from: https://www.ncbi.nlm.nih.gov/pubmed/20967495

26. Powell BJ, Proctor EK, Glisson CA, Kohl PL, Raghavan R, Brownson $\mathrm{RC}$, et al. A mixed methods multiple case study of implementation as usual in children's social service organizations: study protocol Implement Sci [Internet]. 2013 Aug; [cited 2018 Apr 25]; 8:92. Available from: https://www.ncbi.nlm.nih.gov/pubmed/?term=A+mixed+method s+multiple+case+study+of+implementation+as+usual+in+children $\% \mathrm{E}$ $2 \% 80 \% 99$ s+social+service+organizations $\% 3 \mathrm{~A}+$ study+protocol 